\title{
More on Smart Cultural Landscapes: technicalities of the planning processes
}

\author{
Alexandru Calcatinge ${ }^{1^{*}}$ \\ 1"Ion Mincu" University of Architecture and Urbanism, Faculty of Urbanism, Department of Urban \\ Planning and Territorial Development, 010014 Bucharest, Romania
}

\begin{abstract}
This paper will build upon my previous smart cultural landscapes research, by offering a technical overview of the planning processes that the policies are based on. In this respect, I will discuss, in an analytic manner, how the argumentation process should take place from a cultural landscape study. This will take into consideration the proficiencies of a planning professional, the smart characteristics of a cultural landscape policy or study and the relevant steps that should be taken to effectively solve the local rural or urban cultural landscape specific issues. The anticipated results would be to establish a well-known place of cultural landscape studies amongst the local rural and urban development processes.
\end{abstract}

\section{Introduction}

Various studies have shown that cultural landscapes and urban planning are closely related to the evolution of technology and communications, and thus it takes advantage of new technologies to achieve better solutions on the management side. [1] [2] [3]

In this respect, my research for the past two years has been focused on the Smart side of Cultural Landscapes. How to tackle with this concept and what it implies when it comes to the planning process at the local and regional level. In this paper I will focus on the planning and policy making processes and how this can further develop the cultural landscapes into being 'Smart'.

The urban planning process is a strange one. It is overly complex, mostly unclear, and sometimes rusty. In this respect, a major aspect to be discussed in this paper would be the preparation of two new legislative proposals in Romania: The Cultural Patrimony Code and the Territorial Development, Urbanism and Construction Code. Both are in their early stages but are bound to bring significant changes to the urban legislature. Besides those two "case studies", I will bring to the table some of the most prominent planning and cultural schools of thought, to have a complete and wide view on the technicalities of the planning processes.

Thus, having this unique opportunity to be in a time when ground-breaking changes are on the horizon, we must, as an utmost importance, see things into perspective and prepare an integral planning process in urbanism and cultural landscape studies. This will be the

\footnotetext{
*Corresponding author. E-mail address: alexandru.calcatinge@gmail.com
} 
smart component that is currently missing. Throughout this paper you will find terms like urban and urban planning be used more than cultural landscapes, and I feel like I need to clarify this. In the process of creating urban planning projects and documentation, the landscape study is merely a component of the entire stack, with cultural landscape studies being an even smaller one. Thus, I will mostly refer to the planning process as being urban, and this will automatically include the cultural landscape documentation. What are cultural landscapes? The answer to this question will surely extend outside the scope of this paper, but I would just like to reiterate two of my findings on cultural landscapes, as a noticeably short answer to it. First, "the contemporary urban cultural landscape is a space of identity shaping, active and dynamic. Its perception is complex, of phenomenological nature, being both a cultural process and cultural product. The process of social life is directly integrated in the notion of urban landscape" [4] and "the cultural landscape is thus the mirror of the society reflecting all the attributes, features and characteristics of our existence by means of spaces created based on the knowledge acquired in time". [5]

\subsection{The Problem}

First and foremost, let us define the problem we are trying to solve. In a short version, the problem is $>$ the urban (and cultural landscapes) planning process is in danger of becoming irrelevant. Is it really a planning problem, or a development problem? To define it in a definitive matter, we should first know how urban and cultural planning are relevant for the development processes. In this respect, let us take the Romanian example. In our country, urban development is a process based on the outcomes of the rules from local/regional/national urban policies. Thus, the relation is clear, and the solution lies in the way we manage to integrate all the existing material, using clear procedures, integrated and integral thinking on urbanism and cultural landscapes, and a clear way to build an urban argumentative discourse. This is what makes them smart.

\subsection{The Solutions}

This paper will provide one possible solution to the problem stated earlier. Thus, as I see this issue, it could be structured as follows. First, we need to define a culture of planning to determine a feasible and relevant urban practice. Then, we need to create a relevant planning theory that could be the foundation for the local urban practices and schools of thought. Thirdly we need to have an integral approach to urban and cultural landscape planning. Then we need to define the critical aspects of growth and the future of planning and development by establishing a smart way to do planning, that is the culmination of all the solutions enlisted above.

\section{Methodology}

The problem we are shortly discussing here is not going to receive all the possible solutions inside a short paper. It is more suitable to an extended research that could span over several years. What this means is that I find the most suitable research methodology to be a modular one. This paper would be just a module of that research. Modularity would be the foundation of a much wider solution, and each research finding will form the layers of a more complex and dynamic solution. Thus, this module would be about technicalities, the very base of every planning process. 


\subsection{Research strategy}

The strategy followed in this paper will be built following these characteristics:

- Will follow on a clear set of principles

- Will have clear research questions

- Will tackle with all the essential issues of each module

- Will be the base for experimentation and teaching

As it seems, it is straightforward and clear, and all we must do now is to determine the principles to follow. But first, let us determine the relation between theory and methodology. Our research strategy should reveal the process that we follow to determine what we want to show with this study. According to Donald O. Case, "both theory and method must be concerned with our type of explanation (e.g., is our goal to demonstrate that one variable influences another?) and our approach to inquiry (e.g., whether we use a theory to guide observation, or whether we start making observations to build a theory)" and that "methodology is not concerned with substantive assumptions about what is being studied, which is a matter for theory (or, more specifically, for metatheory). Only theory addresses the basic assumptions that we make about the nature of reality". [6] Thus, our concern is to determine the "attempts to formulate possible factors that could be varied systematically in such a way that a corresponding variation in other variables might be observed seemed logical enough". [7] The variables we are working with are planning and culture, and a variation of one, will most certainly determine an equal variation in the other.

Our principles to follow:

- Will not look for a full coverage of the problem in such a short paper

- Will keep a modular approach throughout the paper

- Will show flexibility in dealing with complex subjects

- Will slowly build our argumentation upon layers of systematic research

- Will offer explanations on every layer of research

\subsection{Methods and materials used}

According to Case, "one way to conduct research that is both valid and reliable is to be found in the use of multiple methods and multiple sources of data". [8] In our case, the mostly used method will be the qualitative one, with a twist. First, we will use it to analyse and gather non-numerical data and to gain some insights about motivations and reasons behind ideas and hypotheses that we will encounter over our research.

We will not use the quantitative research method, as it does not offer us any leverage in getting a solution for planning and culture. At least not at this stage and particularly not for this module.

Regarding the study materials, we will focus on specific literature on planning theory, cultural landscape studies and technology.

\section{Results}

As we saw by now, our main research problem would be the irrelevance of cultural landscape and urban planning processes, and in order to get to the solution, we will have to start from the very beginning, which is the understanding of planning. This will lead us to the point where we will be able to sketch a relevant planning theory. At this point, the planning theory would give us a lead on how an integral approach on urban and cultural landscape planning should look, which nevertheless would point to a sustainable and healthy growth. At the end, the results of the research will focus on the technical side of 
planning and will establish a foundation for future endeavours in the fields of data science, blockchain and smart everything (cities, cultural landscapes, homes etc.).

\subsection{Culture of planning}

Urban planning as we know it today has its roots in the architecture and urban planning from the end of the Second World War and was closely related to the consumer culture and the way that architects and public administrations saw the need to seize the opportunity to build something new. According to Andrew Shanken, in the United States "architects embraced planning in the cultural context of the home front, when New Deal, wartime, and post-war planning overlapped". [9] Furthermore, the same Shanken stated that "As Americans lived through the transformation from New Deal to wartime to post-war planning, the city served as a site, both literally and abstractly, for thinking through potential socioeconomic, political, and physical changes". [10] At the same time, in the UK, as Nigel Taylor argues, there is a slight different approach as "after the Second World War, there was much talk of 'planning' in a general sense - that is, state intervention in, and playing a more active role in, the managing and planning of social and economic affairs generally as part of the changed political climate. (...) The prevailing view was that, with the possible exception of regional planning controls over the industry, town and country planning was concerned with the 'physical' environment and was thus most appropriately described as physical planning, as opposed to 'social' and 'economic' planning". [11]

Those two models were the blueprints for planning evolution in the western world. But on the other side of Europe, the end of the Second World War was the point when planning started to follow the Soviet model. This model failed and after the fall of the Berlin wall, the gaps between East and West started to widen even more. It was the time when changes and a lot of catching up had to be done. As "the general plan has been the object of much criticism in view of its evident failure to guide urbanisation and urban development in the required manner". [12] Romania had to follow the Soviet rules, for more than forty years, and now, thirty years since the 1989 revolution, we are still trying to impose new models for planning. The new urban general plan for the capital city started in 2013 and is still in the preliminary stages.

Anyhow, the two planning systems, the eastern and the western one, are quite different and proven hard to change and adapt to new realities, in the case of the soviet model. Those systems have already determined a culture of planning for each country or region that uses them. An history of the culture of planning is out of the scope of this paper, but the most important aspects will be shortly discussed here. One of the interesting aspects is the way architects shifted into planners, and the way Andrew Shanken sees it is important for the overall picture. He argues that "architects groused over the many threats to their profession, including old enemies, such as builders, contractors, and engineers, and new ones, especially government and corporate design bureaus". [13]

The battle was for a clear establishment of the profession into a very diffuse social, economic, and legal landscape. Shanken [14] has a short comparison between doctors, architects, and planners regarding the monopoly status of professional associations, that will establish a tight nexus between major forms of professional activities, from universities to small practices. Each profession created its own association, and between the three examples, the doctors were the firsts to impose regulatory measures for the medical practices. Then followed the architects with their plethora of professional associations that led to a failure to gage all activities. The planner's professional association had an even more difficult start and a short life until the end of the Second World War.

Thus, a new paradigm started, as "the entire western world seemed to be in the throes of a systemic shift marked by, among other things, a move toward centralized planning" [15] 
and it "exhibited figurative qualities, standing in for other ideas, such as the future, better living, comfort, order, and most empathically, the potential for a radical change in the social structure". [16] The eastern planning model was never something to write home about, and all the countries from the former Eastern Bloc have adopted the western model.

In this respect, the new general plan for Bucharest is designed to be a dynamic one, like a pro-active organism, a tool for monitoring, transaction and updating for local territorial beeswax. Romania took the planning model from France after 1989 and failed to improve it and build upon the good points. Nevertheless, professionals in urban planning are mainly concluding that the main general plan needs to have a reactive and pro-active component, to be able to react fast as an important tool in guiding development at different stages, thus being a dynamic regulatory instrument. [17] For the city of Bucharest, they are developing "a three-tiered planning regulation system aimed at governing developments occurring within the city" [18] and are building their conceptual and theoretical framework on three distinct theories: the theory of metropolitan functions, the theory of demand oriented urban life cycle management and science of networks. [19] The concept of the new masterplan lies, as the authors say, at the intersection of urban planning, structural field, functional field, and GIS. [20]

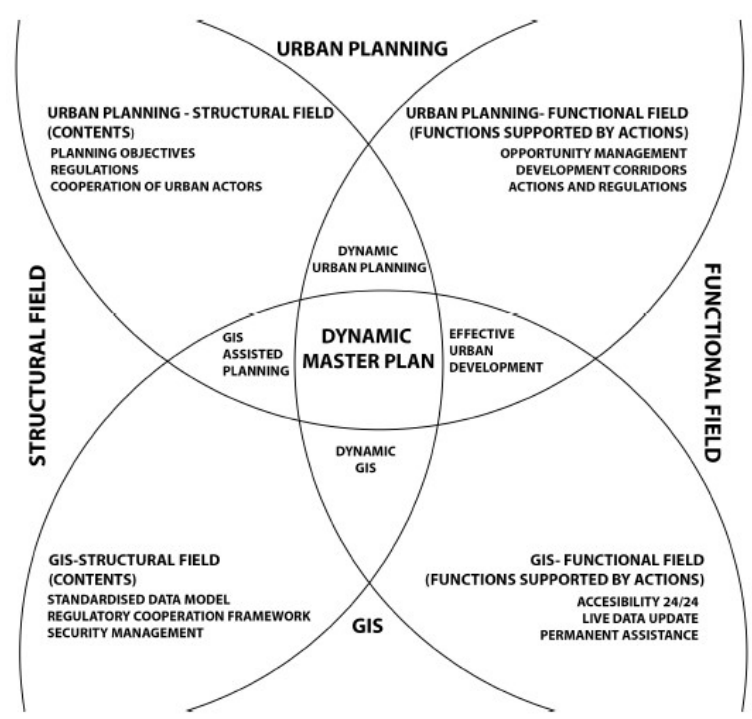

Fig. 1. The concept of the New Dynamic Master Plan for Bucharest. Source: T. Florescu (et. al), The architecture of dynamic planning regulations, Book of Proceedings, 29th Annual AESOP 2015 Congress, July 13-16, Prague, Czech Republic, pp. 2761 - 2769, p. 2764 (2015)

Therefore, what would the culture of planning be in our case? First and foremost, as architects, I see that the distinctive competence is our ability to deal with some of most complex forms and surfaces, to create a functional and liveable space. We deal with space as a metaphor of culture, an abstract entity that we can manage and transform as a tool of social creation, with cultural and economic relations. Furthermore, as urbanists (as we call the profession in Romania), we can configure spaces from micro to macro levels, from local to regional and national levels. We work with different elements such as climate, geographical data, culture, tradition, mentality, demography etcetera, which can be considered as datums; with other elements as actions, public interventions, material actions; with politics, which are the underlying actions that determine the actions, public or private; and elements like institutions, the forefront of urban/regional enactment. 
Planning is a tool used to forecast and develop and has political and legal dimensions. Our culture of planning is comprised of different tools that form a planner's literacy. According to Greg Young, it has three distinct parts: a cultural literacy, an ethical literacy, and a strategic literacy. [21] The last one is the kernel of a professional planner, be it architect, urbanist, or any other profession. Nowadays strategic planning is an important component of any planner's toolkit, as it needs to create plans that integrate the objectives and resources with opportunities at all levels. The urban planner needs to be able to operate with public policies and legal instruments to fulfil his purpose. This makes the planner a good coordinator between law and decision makers, local / regional / central authorities, NGOs, and private sector actors.

The urban planner, through his documentation, needs to build relevant arguments that sustain its endeavour. Those arguments need to be regulated, and this is exactly the scope of the Cultural Patrimony Code and the Territorial Development, Urbanism and Construction Code. And for this, we need a relevant planning theory, which we will discuss in the following sub-chapter.

\subsection{Relevant planning theory}

Now that we know how the culture of planning has emerged, let us talk about relevant theory of planning. Dealing with all the models, concept and theories of planning is out of the scope of this paper, but we will refer to some that we personally find relevant for our contemporary practices. According to Philip Allmendinger the most important theories are systems theory, rational process theory, critical theory, neo-liberal planning theories, pragmatism, advocacy, postmodern planning and post-structuralism and communicative rationality. [22]

Besides Allmendinger, Nigel Taylor also theorized about the evolution of planning theory, about changes in planning thought and paradigms, and in the end the conclusion was simple: it all ends and starts with Faludi's procedural planning theory, as a possible singular planning theory that is constantly discussed, acclaimed or critiqued [23]. One critique comes from Michael J. Thomas, which stated that Faludi's theory is "overwhelmingly focussed on the means of planning and not the ends". [24]

In a paper from 1985, Faludi answers some of its critiques by stating that "it concerns the nature of theory and the object of planning theory as an academic discipline. For good reasons, professionals are convinced that they need both procedural and substantive knowledge". [25] Further sustaining his theories, Faludi sets two important questions to be asked by any planning professional. First is "how does planning reflect the nature of its object of concern" [26] and the second is "which aspects of the environmental demand that we should attend to the inter-relations between such interventions in the environment as o take place". [27] In order to make things simple for other researchers, Faludi answers the questions with his vision on how the environment should be seen. Thus, he proposes that the environment should be seen as a certain configuration of resources that are commonly found on land decision units, link to each other by channels of communication and protected by the land regime; and the environmental planning should be seen as the sum of operational decisions and public environmental measures. [28]

For more than thirty years, those principles were always at the forefront of planning theory, but the question that lies now is how will the planning be in the future? For this question, Allmendinger had a list of nine principles upon which planning should be built. [29] I will not remind all of them here, but I just want to focus on some of them. Thus, his second principles states that "a postmodern planning should be based on an underlying assumption that all processes and procedures are not 'closed', that is, there is no 'best' plan for every situation". [30] Further, three of the principles support the openness of the 
planning process, in order to keep a regularly maintained and updated framework and the last one states that "planners should take a more active and creative role in the sustenance and encouragement of fluid structures and processes". [31]

And this is not all. Besides Allmendinger, another author, Greg Young argues that culture is the salvation of planning. Thus, he said that "in order to revive, planning first needs to capture something of the true dynamism of culture, beyond the fragmented and superficial reflection of culture it usually achieves. At every planning level, culture is addressed in a conceptually fragmented, ad hoc, and frequently opportunistic fashion, that brings cultural inauthenticity to the fore". [32]

For our immediate scope, we need an integrative approach to planning, in which we need coordination between urban planning professionals and legal practitioners. This implies that the urbanists need to have a solid understanding of legal instruments, and urban concepts and jargon should be at the fingertips of any urban lawyer.

The need to codify the urban legislation is imperative, and this can only be done if urban planners, on one side, will adopt a coherent planning theory that is grounded in wellestablished works of theoreticians and practitioners alike, and the legal apparatus will be clarified and simplified in order to support transparency for the implementation and evaluation processes.

\subsection{The smart way}

Throughout my recent research, I wanted to determine the relations between cultural landscapes and open source paradigms, open innovation, and big data, as a possible smart solution for future of planning in urban / regional development. [33]

As an advocate of open source solutions for many years, I try to impose its paradigms in the current planning processes. Most important is that these paradigms are governed by two principles: accessibility and flexibility. But the future is not only open source but also a new technology that is arising and looks promising to all types of operations: blockchain. This new technology is innovative and difficult to comprehend for a non-technical mind, but some authors managed to create non-technical guides to this technology, which is extremely important for us as architects and urbanists. But what is blockchain? Well, it emerged as the technology behind crypto currencies and now is also used in proof-of-work and proof-of-stake distributed consensus mechanisms, crypto token economics, Ethereum and smart contracts, generic crypto token systems, and byzantine fault tolerance distributed consensus. [34] Nevertheless, what makes it a little bit easier to comprehend for us is our knowledge of systems theory and its relationship with planning.

For the start, let us remember a little bit about systems theory in urban planning, a concept that emerged in the 1970s and quickly gained speed into being adopted by professionals. Thus, J. Brian McLoughlin, enchanted by the evolutions in mathematics and computer processing from that time, introduced the concept of systems theory to urban planning "to provide a framework by which interested people may relate the new tools from many fields to the problems of planning cities and regions". [35] Furthermore, George Chadwick is dealing with the same concept and treats it from the same perspectives as McLoughlin, but he considers that "spatial planning, is thus seen as a more particularised branch of a general discipline, whose field may be said to impinge upon psychology, upon scientific method generally, upon general system theory, upon cybernetics, upon operations research and logistics". [36] Thus, for more than fifty years, planning was closely related to the new technologies, and scholars constantly tried to tie those two together. In this respect, Faludi considered that planning itself should be subject to planning and all boiled down to "describing a method by which decisions should be made between alternative forms of 
planning - or let us call them alternative types of space in which the solution to problems must be sought". [37]

Today, based on the blockchain revolution, we are getting a new perspective on systems theory, as "the purpose of the blockchain is to achieve and maintain integrity in distributed systems (...) a distributed system consists of a number of independent computers that cooperate with one another by using communication medium in order to achieve a specific objective without having any centralized element of control or coordination" [38] Blockchain is considered to be "one of the most disruptive technologies of our time. Numerous cities around the world are launching blockchain initiatives as part of the overall efforts toward shaping the urban future. However, the infancy stage of the blockchain industry leads to a severe gap between the knowledge we have, and the actions urban policy makers are taking" [39] The possibilities are endless with this technology, and most certainly it can be used in implementing urban regulations and documentations. In this respect, there are several classifications of blockchain use cases in urban planning: role based, and business model based with applications such as static registry, identity, smart contracts, dynamic registry, payments infrastructure, record keeper, digital asset market. [40] [41]

In a world dominated by blockchain technology and backed up by the open source paradigms that have been taken the world by storm [42], it would be a lot easier to enable a coherent argumentation in urban planning. And coordination, transparency, decentralization, and simplification should be the most important characteristics.

\section{Conclusions}

Looking back to the steps taken to determine the planning process in urban and cultural landscape studies, we can deduct that they were small and focused. The way to make urban planning relevant again is to rethink urban argumentation, to adapt it to dynamic needs of the society by defining a new culture of planning and to adapt the theory to new technologies and techniques. Besides this, it also implies a well-developed planner's literacy based on culture's principles like plenitude, connectivity, diversity, reflexivity, creativity, critical thinking, and sustainability. Thus, urban planning and cultural landscape studies are closely related, as both are based on a similar set of shared documentation structures, and the relevance of one lead automatically to the relevance of the other.

In the end, it al points to coordination and growth. Coordination at the urban planning level is not just informational exchange, it is more of a structuring of data and a coherent way to advocate it, as public administration, legal entities and urban planner all use different dialects of the same language. This should be much easier using new technologies like blockchain, to have a more transparent and decentralized process.

The future of urban planning and cultural landscapes will be closely related to the future of the cities as 'smart' dynamic entities based on smart economy, smart people, smart governance, smart mobility, smart environment, and smart living. For short, smart everything.

\section{References}

1. Ch. Garau, From Territory to Smartphone: Smart Fruition of Cultural Heritage for Dynamic Tourism Development, Planning Practice and Research, 29:3, pp.238-255 (2014)

2. Ch. Garau, Smart paths for advanced management of cultural heritage, Regional Studies, Regional Science, 1:1, pp.286-293 
3. N. G. Blagovidova, N. V. Iudina, 'Smart City' system as an asset of cultural landscape development, IOP Conference Series: Materials Science and Engineering, 775 (2020)

4. Al. Calcatinge, The need for a Cultural Landscape theory: an architect's approach, Urban and Spatial Planning, Volume 12, LIT Verlag, Vienna, p.88 (2012)

5. Al. Calcatinge, The need for a Cultural Landscape theory: an architect's approach, Urban and Spatial Planning, Volume 12, LIT Verlag, Vienna, p.76 (2012)

6. C. O. Case, Looking for information. A survey of research on information seeking, needs, and behavior, $3^{\text {rd }}$ Edition, p.202 (2012)

7. L. P. Steffe, P. W. Thompson, Teaching experiment methodology: underlying principles and essential elements. In: R. Lesh \& A. E. Kelly (Eds.), Research design in mathematics and science education (pp. 267-307). Hillsdale, NJ: Erlbaum, p. 270 (2000)

8. C. O. Case, Looking for information. A survey of research on information seeking, needs, and behavior, $3^{\text {rd }}$ Edition, p.211 (2012)

9. A. M. Shanken, 194X: Architecture, Planning, and Consumer Culture on the American Home Front, University of Minnesota Press, Minneapolis, p. 15 (2009)

10. A. M. Shanken, 194X: Architecture, Planning, and Consumer Culture on the American Home Front, University of Minnesota Press, Minneapolis, p. 16 (2009)

11. N. Taylor, Urban Planning Theory since 1945, Sage Publishing, London, p. 5 (2009)

12. D. J. B. Shaw, The Soviet Urban General Plan and Recent Advances in Soviet Urban Planning, Urban Studies, volume: 20, Issue: 4, page(s): 393-403, p. 393 (1983)

13. A. M. Shanken, 194X: Architecture, Planning, and Consumer Culture on the American Home Front, University of Minnesota Press, Minneapolis, p. 3 (2009)

14. A. M. Shanken, 194X: Architecture, Planning, and Consumer Culture on the American Home Front, University of Minnesota Press, Minneapolis, pp. 7-8 (2009)

15. A. M. Shanken, 194X: Architecture, Planning, and Consumer Culture on the American Home Front, University of Minnesota Press, Minneapolis, p. 15 (2009)

16. A. M. Shanken, 194X: Architecture, Planning, and Consumer Culture on the American Home Front, University of Minnesota Press, Minneapolis, p. 16 (2009)

17. O decadă de planificare urbană în România, 30 june 2014 online: https://arhitectura1906.ro/2014/06/o-decada-de-planificare-spatiala-in-romania/ accessed on 10th aprile 2020

18. T. Florescu (et. al), The architecture of dynamic planning regulations, Book of Proceedings, $29^{\text {th }}$ Annual AESOP 2015 Congress, July 13-16, Prague, Czech Republic, pp. $2761-2769$, p. 2761 (2015)

19. T. Florescu (et. al), The architecture of dynamic planning regulations, Book of Proceedings, $29^{\text {th }}$ Annual AESOP 2015 Congress, July 13-16, Prague, Czech Republic, pp. $2761-2769$, p. 2764 (2015)

20. T. Florescu (et. al), The architecture of dynamic planning regulations, Book of Proceedings, $29^{\text {th }}$ Annual AESOP 2015 Congress, July 13-16, Prague, Czech Republic, pp. $2761-2769$, p. 2764 (2015)

21. G. Young, Reshaping Planning with Culture, Urban and Regional Planning and Development Series, Ashgate, Burlington, pp.106-110 (2008)

22. P. Allmendinger, Planning Theory, $2^{\text {nd }}$ Edition, Palgrave Macmillan, Hampshire (2009)

23. N. Taylor, Urban Planning Theory since 1945, Sage Publishing, London, p. 167 (2009) 
24. M. J. Thomas, The procedural planning theory of A. Faludi. Journal of Environmental Planning and Management, Planning Outlook, Volume: 22, Issue: 2, pp. 72-76, p.72 (1979)

25. A. Faludi, A decision-centred view of Environmental Planning. Landscape Planning, Volume: 12, pp. 239-256, p. 240 (1985)

26. A. Faludi, A decision-centred view of Environmental Planning. Landscape Planning, Volume: 12, pp. 239-256, p. 240 (1985)

27. A. Faludi, A decision-centred view of Environmental Planning. Landscape Planning, Volume: 12, pp. 239-256, p. 241 (1985)

28. A. Faludi, A decision-centred view of Environmental Planning. Landscape Planning, Volume: 12, pp. 239-256, p. 241 (1985)

29. P. Allmendinger, Planning Theory, $2^{\text {nd }}$ Edition, Palgrave Macmillan, Hampshire, pp.238-239 (2009)

30. P. Allmendinger, Planning Theory, $2^{\text {nd }}$ Edition, Palgrave Macmillan, Hampshire, p. 238 (2009)

31. P. Allmendinger, Planning Theory, $2^{\text {nd }}$ Edition, Palgrave Macmillan, Hampshire, p. 239 (2009)

32. G. Young, Reshaping Planning with Culture, Urban and Regional Planning and Development Series, Ashgate, Burlington, p.5 (2008)

33. Al. Calcatinge, Open source paradigms in urban and rural development, $6^{\text {th }}$ International Conference on Thermal Equipment, Renewable Energy and Rural Development TE-RE-RD 2017 Proceedings, pp. 323 - 329 (2017)

34. C. Shen and F. Pena-Mora, Blockchain for Cities - A Systematic Literature Review, IEEE Access, Volume 6 (2018)

35. J. B. McLoughlin, Urban and Regional Planning. A systems approach, Faber and Faber, London, p.17 (1969)

36. G. Chadwick, A systems view of planning. Towards a theory of the urban and regional planning process, $2^{\text {nd }}$ Edition, Pergamon Press, pp. 24-25 (1978)

37. A. Faludi, The "Systems View" and planning theory, Socio-Econ. Plan. Sci. Vol. 7, pp. 67-77, p. 75 (1973)

38. D. Drescher, Blockchain Basics: A Non-Technical Introduction in 25 Steps, Apress, p. 17 (2017)

39. C. Shen and F. Pena-Mora, Blockchain for Cities - A Systematic Literature Review, IEEE Access, Volume 6, p. 76787 (2018)

40. C. Shen and F. Pena-Mora, Blockchain for Cities - A Systematic Literature Review, IEEE Access, Volume 6, p. 76810 (2018)

41. C. Shen and F. Pena-Mora, Blockchain for Cities - A Systematic Literature Review, IEEE Access, Volume 6, p. 76787 (2018)

42. G. Haff, How Open Source ate Software. Understanding the Open Source Movement and So Much More, Apress (2018) 